\title{
Cross-cultural Analysis of Cultural Conflicts in Film Gua Sha*
}

\author{
Lei $\mathrm{Li}$ \\ Foreign Language Department \\ Henan University of Traditional Chinese Medicine \\ Zhengzhou, China
}

\begin{abstract}
The film "Gua Sha" tells about the legal disputes and family conflicts of Xu Datong, a Chinese-American, after his old father went to the United States and scratched his son to treat his diseases, reflecting the differences between Chinese and American cultures. This paper analyzes the cultural conflicts hidden behind the plot and the correct solutions from the perspective of the plot design of the film.
\end{abstract}

\section{Keywords—Gua Sha; plot design; cultural conflict}

\section{INTRODUCTION}

The film "Gua Sha" (Scraping Treatment) is directed by Zheng Xiaolong and produced in 2001. Taking misunderstandings of the scraping therapy as a main line, the film describes stories of Chinese people in foreign countries. Living in the conflict between eastern and western cultures, oversea Chinese people fell into various difficulties, and finally went through them with sincerity and love. The story was supposed to happen in the city of St. Louis, on the Mississippi River in Central America.

\section{PlOT DESIGN}

\section{A. Prelude Bedding}

The film begins with the appearance of the red Chinese characters "Gua Sha", which expresses a depressed, heavy atmosphere, so that the audience will be full of expectations of the film's contents. The prelude of the film is the joyous scene of Xu Datong's winning the company's rewards. The statements he made while receiving the award reflect the recognition and respect won by Chinese Americans through good efforts, which embodies the spirit of "American Dream". However, the happy rhythm is also interspersed with some discordant "episodes", which set bedding for the following development of the story.

\section{B. Plot Design of "Crisis"}

\section{1) Xu Datong's "Violent" Tendency}

When Datong's son Dennis and the boss's son Paul is playing video games, Dennis hits Paul because of small things. In fact, it's just a small affair between children, which needs not to be too concerned about. However, having just This article is sponsored by Henan Soft Science Project (No. 152400410137; 162400410336) and Henan planning project of the philosophy and social sciences (No. 2016BYY007; 2016CYY024). won the honor of the boss and being grateful, $\mathrm{Xu}$ Datong asks his son to apologize to keep the boss's dignity. But the child has his own thoughts and doesn't want to apologize. He spits to Paul, which angers Datong. Datong hits Dennis on the head, which makes the child cry in public. Datong's wife and father both remind him of stopping doing that, but Datong doesn't take their advice. He thinks that he's maintaining the boss's dignity and his own dignity of being a father. But he doesn't realize that he hasn't established his status within the child's heart, and has made his boss astonished. Later, in the court hearing, his boss presents as a witness. He states the scene as an example, but is used by the accuser's lawyer as good evidence. This makes Xu Datong angry and excited. He comes into a rage in the court, which makes the judge decide to put the case into the formal trial stage. The march of anti-violence in front of his company and the case of being charged for violence in his game software both laid a foundation for his being charged for being violent.

\section{2) Negligence of Children Education}

Though Datong and his wife Jian Ning provides great supports to their son's material life, they seldom show concern to the child's spiritual life. They are always busy working and seldom make deep communications with the child. They have lots of bad parenting habits of Chinese parents, such as scolding the child in public, ordering the child to obey their demands, neglecting the child's feelings, etc. A typical example is that when Datong comes back home, he doesn't realize the mistake of hitting the child in public, which makes the child depressed. He thinks that the child is being too sensitive and narrow-minded. The child's grandpa uses a Chinese saying to moderate their relation, which is "Beating and scolding reflects love. Without teaching and correcting, a person cannot grow into the maturity." Datong interprets the sentence to the child vaguely, which makes the child believe that beating others is a reflection of love. Without further explanation, Datong just laughs at it. The child's habit of beating others is the result of negligence of education. Children in this age are curious, doubtful and confused about the world, being good at observing and simulating others. Living in America, the child cannot deeply understand the cultural differences and cannot easily accept the Chinese lifestyle presented by his grandpa coming from remote China. As a father, $\mathrm{Xu}$ Datong should have grasped the chance to explain Chinese culture to 
him and reduce cultural misunderstandings. But he doesn't, which results in the further manifestations of communication obstacles and culture shock.

\section{West}

3) Great Cultural Differences between China and the

The film reflects the differences between Chinese and Western cultures. For example, the artistic image of Monkey King has different impressions on Chinese and western audience. In China, Sun Wukong (The Monkey King) is widely known, taken as the typical representative rebel against the feudal authority, praising virtue and punishing vice. But he is described as a stubborn, obstreperous and despicable Chinese monkey. Traditional Chinese Medicine (TCM) terms, such as Dantian (the pubic region), Jing (essence, spirits), qi and Qijing Bamai (the Eight Extra Channels), are spoken randomly without evidence, which is beyond their understandings. American court puts emphasis on evidences, but scraping treatment hasn't been accepted by the American medical circle, which leads to a conflict. During the court statements, Xu Datong talks about asking other people to bring a folk prescription from Beijing to treat their child's disease, which arouses his wife's strong rejection. In the face of his boss, Xu Datong closed Dennis' game machine and asks him to apologize to Paul. Growing up in a patriarchal society, $\mathrm{Xu}$ Datong thinks that children should obey parents' orders, be obedient and respect others. However, he doesn't know that this education way is unacceptable in America. Besides, his behavior cannot arouse the child's recognition due to the lack of respect and understanding towards him.

\section{Contradictions and Conflicts with Climaxes}

\section{1)Contradiction Caused by the Scraping Treatment}

When Dennis' abdomen is painful, Datong's father cannot understand English words on the medicine bottle and decides to scrape him to make a treatment. When Datong's father goes to see his friend, he finds that his friend lying on the bus due to the heart attack. They are sent to the police station, where Datong goes to fetch his father. While Datong's out, he leaves sleeping Dennis alone at home. When they go back home, Dennis has broken his head and then is sent to the hospital. After that, the scraping mark is noticed by the social worker in the hospital. They send the child to the child custody department and separate him from his parents. As a traditional TCM treatment, scraping treatment has aroused such a big confusion, which seems unexpected but rational in such a special background.

\section{2) Conflict in Courtroom Debate}

The fierce conflict between Xu Datong and the opposing lawyers in the court is mainly concerned with the rationality, legitimacy and the violent inclination of him. Language conflict originates from the different thoughts and ideas. Although the opposing lawyers provoke $\mathrm{Xu}$ intentionally, the most important reason of his failure in the charge is lack of correct explanation and rational defense to his personalities and Chinese culture. Without knowledge of American legal procedures, $\mathrm{Xu}$ Datong refuses to accept his lawyer's suggestions, becomes emotional and finally fails in the court.

\section{3) Misunderstandings of American Friends}

Compared to the failure in the court, the most unbearable thing for $\mathrm{Xu}$ Datong is that his American friends do not understand him. His friend, also his boss, states in the court that he should not scold and beat his children. While $\mathrm{Xu}$ Datong thinks that beating the child is meant to teach him and keep the boss's dignity. Americans cannot understand the emphasis of Chinese towards face and human relations and cannot understand his behavior of protecting his father by hiding the truth of scraping therapy. Chinese concept of filial piety, including respect towards parents and responsibility to the family, is a reflection of the collectivism concept. Due to the concept of individualism in America, his friends cannot understand these behaviors.

\section{4) Outbreak of Family Conflicts}

Due to $\mathrm{Xu}$ Datong's failure in the court, Dennis must be kept away from his father and be isolated in the orphanage. Anxious Jian Ning attributes all this to Xu Datong's personal fault, quarrels with him and determines to live separately. The emotional pain and helplessness undoubtedly worsens the predicament of $\mathrm{Xu}$ Datong. The original happy harmonious family becomes separated due to the lawsuit. This is a tragedy, but also an inevitable result of the development of the plot.

\section{The Final Successful Outcome}

On Christmas Eve, in order to meet his son, Xu Datong risks his life to climb the outer wall of a tall building, since the doorkeeper doesn't let him in. His great parental love moves every audience at present. Later, Xu Datong's boss goes to China to experience the scraping treatment in person and finally accepts the traditional treatment method. Just on Christmas Eve, he requests the court to cancel the punishment of Xu Datong, comes to Xu's home, apologizes to him sincerely and wishes them happiness. This happy ending implies that cultural differences are communicable and can be solved through mutual efforts to achieve a harmonious and mutually beneficial result.

\section{CUltural CONFLICT AND SOLUTION IN THE FILM}

\section{A. Cultural Conflicts in the Film}

The story plot seems accidental, but actually has inevitable hidden reasons. These deep-seated factors are hidden and buried in the film, which need in-depth excavation and exploration. The above-mentioned contradictions and conflicts actually are rooted in different cultural backgrounds of China and the United States, which not only include the differences of treatment methods between western medicine and the traditional Chinese medicine, but also the differences of Chinese and western ways of thinking, morality and educational concepts. These differences are all reflected in the accident that this immigrant family has experienced. It can be said that the special experience of this family is a concentrated reflection of the success and failure experienced by immigrants, and is a typical case of cultural conflict. The cultural conflict is rooted in the cultural centralism. Xu Datong embodies many Chinese people's inherent ideas and ways of doing things, 
such as the seniority rules, filial piety, collectivism, faith to friends and other concepts, reflecting the inherent characteristics of the relation society in China and the incompatibility of this way of doing things in the western society. ${ }^{[1]}$

Chinese philosophy is represented by Confucianism and Taoism. The philosophy of Confucius and Mencius emphasizes "benevolence, righteousness, ritual, wisdom and faith", seeking for the norm and order of human relations and social relations. Taoist philosophy advocates "Yin, Yang, Five Elements and Eight Diagrams", which thinks that all things in the universe are dialectically connected in the unity of opposites. In contrast, western philosophy pays attention to scientific, rational, analytical and empirical thinking. Based on this, western medicine stresses science-oriented means of verification. Western medicine theory can not explain the concept of Chinese medicine, such as meridians, qi and blood. Therefore, Xu Datong can not come up with strong English evidences in court to persuade the judge. The prosecution lawyers take the image of the Monkey King in "Journey to the West" as an example to deduct that Xu Datong has designed his game software based on the violent tendency in this novel. This reflects the obstacles encountered by traditional Chinese culture in oversea publication, but also reflects the great differences between the Chinese and Western thinking and expressions. ${ }^{[2]}$

\section{B. The Incorrect Solution}

$\mathrm{Xu}$ Datong has experienced scraping treatment in his childhood. Therefore, he thought that this is normal, ignoring the fact that most Americans have not experienced the scraping treatment. As a result, he did not tell his defense counsel about the scraping incident before the court hearing, nor did he realize that the scraping treatment was the real reason that the child was quarantined. This attitude of taking it for granted, and the lack of active communication and interpretation leads to more and more misunderstandings and obvious barriers. Living in a foreign country, he still upholds the ethical and moral concepts of the traditional Chinese culture, shouldering responsibilities and hiding shortcomings for his father. However, he does not realize that his actions and American culture are incompatible. The American court values facts and evidences. Although there is no moral fault, due to a false statement of $\mathrm{Xu}$ Datong in the court, he is considered to have faults in the law. In his speech, he says that the United States is a place full of opportunities. But in the subsequent actions, he lacks sufficient attention to American culture, leading to cultural misreading and misunderstanding.

$\mathrm{Xu}$ Datong's father can be called an intellectual in China, but becomes "dumb and deaf" after coming to the United States. He does not understand other people's words and can not express their ideas. The unfamiliar surrounding environment, the death of his old friend, the lawsuit disputes met by his son make him feel that they do not belong to this strange culture, and ultimately leads him to leave and return to their homeland, back to his familiar culture. He doesn't want to learn English instructions on medicinal bottles and how to use the knife and fork. Instead, he chooses to treat diseases with traditional scraping method, use chopsticks and teach his grandson to learn the Chinese pronunciation of chopsticks. Being unwilling to accept and adapt to the foreign culture, eventually he is not able to integrate into the American society. Instead, he chooses to return to the familiar living environment of the motherland. Xu's wife Jian seems to be better integrated into American society. She asks the child to speak English at home, tries to adapt to the western-style way of life, using a fork instead of chopsticks. But when the family suffers a crisis, she could not think of a good way to convince the judges and lawyers, but chooses to escape, separates from Datong to keep the custody of the child.

$\mathrm{Xu}$ Datong's crisis reflects that based on their own cultural orientation, living in the mainstream culture of the United States, the traditional Chinese culture is taken as a "sub-culture" in the American society, which can easily be seen as a strange thing and receive the group's criticism. It is difficult to integrate into the mainstream American social groups. Under the influence of ethnocentrism, Xu Datong is proud of traditional Chinese culture, while Americans think that their civilization is the more advanced and correct. The resulted cultural stereotypes and prejudices constitute barriers and harms to intercultural communication, and the social sense of belonging formed by one's own cultural creed is narrow and exclusive, with the view that one's culture is normal and natural. During the comparison between different cultures, each of them will naturally raise their own culture and belittle the culture of others. ${ }^{[3]}$

\section{CONCLUSION}

The story in the film tells us that aggressive or negative attitudes are not helpful in solving the cultural conflict, but will make the situation more serious. Although the plot of the film is processed through art, we can see some real reflection of the real life. In face of the cultural conflict, both sides should abandon ethnocentrism, take a positive attitude of cultural relativism, keep calm and reasonable, choose appropriate and reasonable methods, take a more complete cultural interpretation and interpretation to solve the gap and disputes of cultural differences and achieve equal cultural communication and exchange. Xu Datong's name indicates that "the world is the same", containing good wishes and ideals of effective realization of cultural communication, and reflecting the possibility of achieving a common ground while reserving differences, mutual respect and mutual integration.

Scraping treatment is a key line in the film. As a kind of TCM treatment, scraping treatment reflects the magic curative effects of TCM culture, which is an inseparable part of traditional Chinese culture, and a great treasure for the humankind. Therefore, finding proper ways to translate and interpret the cultural connotations of TCM would contribute to the introduction and publication of Chinese culture throughout the world. With the increase of international communications and trade, people get to know different cultures more and more comprehensively. Maintenance of cultural features and mutual understandings of different cultures are future objectives of development. 


\section{REFERENCES}

[1] M. Zheng, Differences between the Chinese and Western Cultures behind the film Gua Sha, Film Literature, vol. 02, pp. 108-109, February 2012.

[2] L.L. Sun, Lu Xinxin, Conflicts and Differences of Chinese and Western Cultures Reflected by Gua Sha, Film Review, vol. 15, pp. 20-21, August 2009.

[3] W.S. Wu, H.X. Yan. Brief Introduction to Intercultural Communication, Beijing: Commercial Press, 2009, pp. 53-57. 